\title{
A STUDY ON THE ENDOSCOPIC SINUS SURGERY OVER THE PERIOD OF 9 YEARS
}

\author{
Maqbool Raza, Atif Rafique, Shahid Farooq Khattak, Muhammad Ali*, Adil Aleem**, Muhammad Zubair ${ }^{* * *}$ \\ Combined Military Hospital Multan/National University of Medical Sciences (NUMS) Pakistan, *Combined Military Hospital /National \\ University of Medical Sciences (NUMS) Rawalpindi Pakistan, ${ }^{* *}$ Combined Military Hospital Quetta/National University of Medical Sciences \\ (NUMS) Pakistan, ${ }^{* * *}$ Combined Military Hospital Kohat/National University of Medical Sciences (NUMS) Pakistan
}

\begin{abstract}
Objective: To share experience of 1000 patients who underwent functional endoscopic sinus surgery (FESS) in 4 different hospitals for various diseases over span of 9 years.

Study Design: Prospective observational study.

Place and Duration of Study: Sheikh Khalifa Hospital Muzaffarabad, Combined Military Hospital Sialkot, Pak Emirates Military Hospital Rawalpindi and Combined Military Hospital Quetta, from Jun 2009 to Jun 2018.

Methodology: We included 1000 patients who underwent Functional endoscopic sinus surgery (FESS) in four different military hospitals, suffering with various diseases discussed later. Patients were operated after failure to get response to medical therapy. All the patients had preoperative endoscopic examination and CT-scan paranasal sinuses (PNS) done for disease assessment. Patients were examined post operatively at 1, 15 days and 2 months. All patients were documented for the level of satisfaction at end of 2 months post-operative period.

Results: Most patients were suffering from rhino sinusitis $364(36.4 \%)$. Bilateral ethmoidal polyps constituted the second largest group at $289(28.9 \%)$ patients. About $837(83.7 \%)$ of patients were completely free of symptom, $104(10.4 \%)$ with partial improvement whereas, 59 (5.9\%) patients did not report any improvement in symptoms. $899(89.9 \%)$ of patients were discharged on their first post operation day meaning less hospital stay and quick recovery.

Conclusion: Functional endoscopic sinus surgery (FESS) can be employed to treatment variety of common nasal diseases (chronic rhino-sinusitis, nasal polyps) and non-nasal diseases like cerebrospinal fluid (CSF) rhinorrhea and as approach to skull base. This method of treatment was quite effective in alleviating symptoms of patients.
\end{abstract}

Keywords: Chronic rhino sinusitis, Functional endoscopic sinus surgery, Mucociliary clearance, Nasal polyp, Osteo-meatal complex.

\footnotetext{
This is an Open Access article distributed under the terms of the Creative Commons Attribution License (http://creativecommons.org/licenses/by/4.0), which permits unrestricted use, distribution, and reproduction in any medium, provided the original work is properly cited.
}

\section{INTRODUCTION}

Paranasal sinus surgery has progressed as new and innovative techniques in exposure and visualization have developed. By 1868, the use of anterior rhinoscopy was routinely practiced, and external approaches to the paranasal sinuses were subsequently developed and refined. The canine fossa approach to the maxillary sinus was described by George Caldwell in 1893. The first endoscopic examination of the nose was performed by Hirshman in 1901 using a modified cystoscope, just as the Caldwell-Luc procedure was gaining popularity for the treatment of chronic sinusits ${ }^{1}$.

With the development of endoscopes,

Correspondence: Dr Maqbool Raza, Associate Professor, ENT Department, CMH Multan Pakistan

Received: 06 Jul 2020; revised received: 20 Nov 2020; accepted: 25 Nov 2020
Messerklinger was able to carefully study both the anatomy and the pathophysiology of the paranasal sinuses. His collection of images and experience was eventually published in 1978 and is now widely considered the major reference work for endoscopic diagnosis ${ }^{2}$. Improvements in both endoscopes and sinus instrumentation developed as interest grew in the United States. Stammberger, Messerklinger's former resident, and Kennedy, who had observed Messerklinger's technique, eventually began teaching endoscopic sinus techniques outside of Germany and Austria ${ }^{3}$.

FESS has revolutionized the ability to diagnose and treat paranasal sinus disease with the help of endoscopes and computed tomographic (CT) scanning 4 . These procedures can be performed under general anesthesia. Office procedure 
can be done under local anesthesia. The specific structures that must be identified and assessed for disease during the examination are the middle turbinate and the middle meatus (osteomeatal complex) $)^{5}$.

The concept of FESS has recently been widely accepted with reasoning all over the world and supported by rhinologist (The term "functional" was introduced to distinguish this type of endoscopic surgery from non-endoscopic, "conventional"procedures) ${ }^{6}$, So main aim of FESS is to preserve the mucociliary function by preserving the protective mucosal layer of nose and paranasal sinuses, to make paranasal sinuses healthy, restore their function by maintaining their ventilation through the individual Ostia7. Functional endoscopic sinus surgery may be used as a term which represents range of procedures in the sinuses depending upon extension of the disease ${ }^{8}$.

With the advent of FESS it has become very easy to assess the problem by the endoscopic examination, remove the disease, restore the ventilation and preserve the mucociliary clearance by preserving the mucosa. In FESS all the sinuses are taken care of simultaneously \& Polypectomies done. For maxillary problem, middle meatal antrostomy that is widening of the natural maxillary ostium in the middle meatus is done and the maxillary sinus mucosa is left intact ${ }^{9}$. For ethmoid disease, ethmoidectomy that is opening and removal of the bulla ethmoidalis (anterior ethmoids). Frontal recess clearance is done by cleaning of the frontal recess at the frontal ostium off the polyps. The frontal sinus mucosa is left intact \& frontal ostium not touched. Sphenoid disease is dealt by widening of the natural sphenoid ostium and cleaning the sphenoid sinus off secretions and polyps. The sphenoid sinus mucosa is left intact. Combination of different procedures depends upon the extent of disease ${ }^{10}$.

The aim of this study was to share our experience of endoscopic surgery of various diseases of head (nose) in Sheikh Khalifa Hospital, Muzaffarabad, CMH Sialkot, Pak Emirates Military hospital Rawalpindi and CMH Quetta.

\section{METHODOLOGY}

This 9 years prospective observational study was carried at four different hospitals (Sheikh Khalifa Hospital Muzaffarabad, CMH Sialkot, Pak Emirates Military Hospital Rawalpindi and CMH Quetta) from June 2009 to June 2018, after getting approval from hospital ethics committees. 1000 Cases which underwent FESS, from both gender between 15 to 65 years of age were included using consective sampling technique.

Through history and nasal examination of all the patients, using $0^{\circ}$ and $30^{\circ}$ rigid nasal endoscopes was done in all cases. CT scans PNS plain in both coronal and axial planes using $5 \mathrm{~mm}$ cuts were obtained as standard in all cases. Patients were prepared for FESS where applicable. They were treated with anti-allergic, systemic steroids and nasal decongestants before surgery. After informed consent, all these cases were operated. All the patients were advised to have regular follow up for at least 2 months. Patients having previous history of surgery were also included in this study. Patients with previous history of trauma or known cases of DNS were also included in this study. Patients which were excluded were unilateral nasal growths with suspicion of malignancy on histopathology, and head \& neck tumors with regional metastasis. These results were analyzed by using Statistical Package of Social Sciences (SPSS) version 17. Frequencies and percentages were calculated for categorical data. Mean and standard deviation were calculated for quantitate data. Microsoft office 2010 was used for generating charts.

\section{RESULTS}

In this 9 year period 1000 cases of FESS were done in 4 hospitals around Pakistan. The patients belonged to both genders and age ranged between 15 to 65 years. The mean age of patients was $34.3 \pm 7.2$ years. Total patients operated were 1000 out of which 148 (14.8\%) cases were treated at Sheikh Khalifa Hospital, Muzaffarabad and $74(7.4 \%)$ cases were treated at $\mathrm{CMH}$ Sialkot. About $580(58 \%)$ cases were treated at Pak 
Emirates Military Hospital Rawalpindi and 198 $(19.8 \%)$ cases at CMH Quetta.

Types of Cases in this study are shown in table-I. Out of 1000 cases 364 (36.4\%) were of rhino sinusitis, $289(28.9 \%)$ cases were of bilateral

Table-I: Disease wise distribution of cases.

\begin{tabular}{l|c|c}
\hline Diseases & $\mathbf{n}(\mathbf{\%})$ & $\begin{array}{c}\text { Valid } \\
\text { Percentage }\end{array}$ \\
\hline Chronic rhinosinusitis & $364(36.4)$ & 36.4 \\
\hline Ethmoidal polyps & $289(28.9)$ & 28.9 \\
\hline Enlarged turbinate & $45(4.5)$ & 4.5 \\
\hline Inverted papilloma & $32(3.2)$ & 3.2 \\
\hline Antrochoanal polyp & $32(3.2)$ & 3.2 \\
\hline Fungal sinusitis & $103(10.3)$ & 10.32 \\
\hline Orbital cellulitis & $32(3.2)$ & 3.2 \\
\hline Endoscopic DCR & $39(3.9)$ & 3.9 \\
\hline Skull Base Surgeries & $10(1.0)$ & 1.0 \\
\hline Miscellaneous & $54(5.4)$ & 5.4 \\
\hline Total & $1000(100)$ & 100.0 \\
\hline
\end{tabular}

Table-II: Distribution of cases for miscellaneous cases.

\begin{tabular}{l|c|c}
\hline Diseases & $\mathbf{n ~ ( \% )}$ & $\begin{array}{c}\text { Valid } \\
\text { Percentage }\end{array}$ \\
\hline Epistaxis & $15(1.5)$ & 1.5 \\
\hline Revision Surgery & $25(2.5)$ & 2.5 \\
\hline Foreign body & $7(0.7)$ & 0.7 \\
\hline CSF Leak & $2(0.2)$ & 0.2 \\
\hline Adenocarcinoma & $1(0.1)$ & 0.1 \\
\hline Esthsioblastoma & $2(0.2)$ & 0.2 \\
\hline Total & $54(5.4)$ & 5.4 \\
\hline
\end{tabular}

ethmoidal polyps, 45 (4.5\%) cases were of nasal obstruction due to enlarged turbinates' for which endoscopic turbinoplasty was done. Thirty two $(3.2 \%)$ out of 1000 cases were of antrochoanal polyp. Fungal sinusitis was diagnosed and treated in 102 patients $(10.2 \%)$. Inverted papilloma cases were $32(3.2 \%)$. Out of 1000 cases, patients of Orbital cellulitis were $32(3.2 \%)$, operated for skull base surgeries were $10(1 \%)$, operated for endoscopic DCR were $39(3.9 \%)$ and Miscellaneous were $54(5.4 \%)$. Out of 54 miscellaneous cases further break up is shown in table-II (revision surgery 25 , epistaxis 15 , foreign body 7 , CSF leak 2, adenocarcinoma 1, esthesioblastoma 2 , choanal atresia 2).

Mostly 899 (89.9\%) the patients were discharged on their first post operation day and the other $101(10.1 \%)$ on 2 nd or 3rd post operation day depending upon their respective complications. $837(83.7 \%)$ of patients were completely free of symptom, $104(10.4 \%)$ with partial improvement whereas, 59 (5.9\%) patients did not report any improvement in symptoms. Response of patient symptoms at 2 months post operatively is shown in figure.

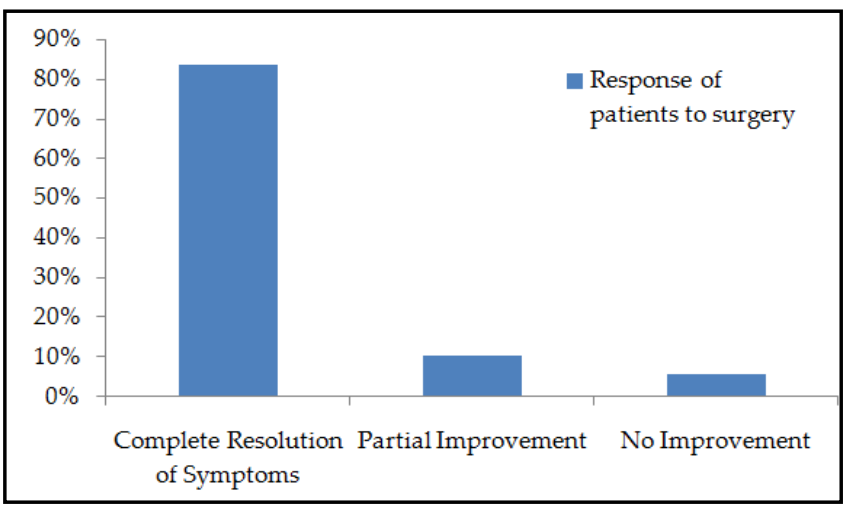

Figure: Response of patients to FESS at completion of 2 months.

\section{DISCUSSION}

Endoscopic sinus surgery is already a gold standard in developed countries for treatment of most of nasal and paranasal sinuses diseases because of superior visualization and ability to reach areas which were inaccessible previously11,12. FESS is relatively new to third world countries like Pakistan because of high cost of procurement and lack of technical expertise in this region. However, despite being late in starting in endoscopic sinus surgery various centers are catching up rapidly to this revolution in ENT. In this study, we have tried to share our experience of FESS over span of 9 years in 4 hospitals around Pakistan.

In our study, we employed FESS to tackle variety of problems being encountered. Chronic rhino sinusitis was the commonest problem for which FESS was utilized at our institutions and constituted $36.4 \%$ of all operated cases. In a study done by Chopra et al13, 38\% of patients operated through FESS had chronic rhinosinusitis which is comparable with our study implying that chronic rhinosinusitis is commonest entity for which FESS is used. In another study, done by Razzak et 
$a l$, the number of patients with chronic sinusitis constituted about $31.67 \%$ of all cases operated with FESS14. All these studies show that in centers where FESS is used to tackle variety of nasal diseases patients of chronic rhino sinusitis constitutes the bulk.

Ethmoidal polyposis is another common problem being faced by Rhinologist throughout world. In our study $28.9 \%$ of cases operated through FESS were of ethmoidal polyps. In another study done by Siam et al, $40 \%$ of patients undergoing Fess had problem of nasal polyposis ${ }^{15}$. In another study patients of nasal polyps constituted $36.67 \%$ of patients who underwent FESS14.

FESS has an advantage of superior visualization of advanced rigid endoscopes and therefore can be used to address variety of nasal and allied problems. In our study in addition to routine nasal diseases FESS was employed to encounter other relatively uncommon but difficult situations. In our study $3.9 \%$ of patients were of endoscopic DCR, $0.2 \%$ of patients were of CSF leak repair and $1.5 \%$ patients were of epistaxis. Therefore showing range of situations in which FESS can be beneficial. In a study done by Qureshi et al, Fess was employed to tackle variety of conditions and their $14 \%$ cases were of endoscopic DCR, CSF repair constituted $5 \%$ of their study subjects and $2.3 \%$ of their patients treated were of epistaxis ${ }^{16}$. In another study done by Raza et al, FESS was used to do advanced surgeries involving skull base and orbits, showing true spectrum of diseases being treated ${ }^{17}$. Results of this study also validates that FESS has started to replace conventional nasal surgery in our centers and has use in treating variety of disease entities.

FESS is very effective in alleviating symptoms of nasal diseases. In our study $83.7 \%$ of patients were completely free of symptoms at 2 months post operatively furthermore $10.4 \%$ showed partial improvement establishing the efficacy of FESS in treating various diseases. In a study carried out by Razzak et al14, complete relief of symptoms was noted in $81.67 \%$ of treated cases which is in line with our study. In another study
$82 \%$ of patients were symptom free after 3 months of surgery cementing role FESS in treatment ${ }^{18}$. Overall FESS was found to be very effective mode of treatment in various studies ${ }^{9,10}$.

FESS can be employed to treatment variety of common nasal diseases (chronic rhino-sinusitis, nasal polyps) and non-nasal diseases like CSF rhinorrhea and as approach to skull base. This method of treatment was quite effective in alleviating symptoms of patients.

\section{CONFLICT OF INTEREST}

This study has no conflict of interest to be declared by any author.

\section{REFERENCES}

1. Raikundalia MD, Cheng TZ, Truong T, Kuchibhatla M, Ryu J, Abi Hachem R, et al. Factors associated with opioid use after endoscopic sinus surgery. Laryn 2019; 129(8): 1751-55.

2. Van Der Veen J, Seys SF, Timmermans M, Levie P, Jorissen M, Fokkens WJ, et al. Real-life study showing uncontrolled rhinosinusitis after sinus surgery in a tertiary referral centre. J Allergy 2017; 72(2): 282-90.

3. Kane KJ. The early history and development of functional endoscopic sinus surgery. J Laryngol Otol 2020; 134(1): 8-13.

4. Ghori SM, Aziz B, Rashid A, Pal MB. An analysis of functional endoscopic sinus surgery (FESS) for sino-nasal disease. Pak J Med Health Sci 2012; 6(4): 827-30.

5. Fetta M, Tsilis NS, Segas JV, Nikolopoulos TP, Vlastarakos PV. Functional endoscopic sinus surgery improves the quality of life in children suffering from chronic rhinosinusitis with nasal polyps. Int J ped Otolaryngol 2017; 100(1): 145-48.

6. Lund VJ, Mackay IS. Outcome assessment of endoscopic sinus surgery. J Soc Med 1994; 87(2): 70-72.

7. Khan AA, Siddiqui AH, Sohail Z. Effectiveness of functional endoscopic sinus surgery (FESS) in the treatment of chronic rhino-sinusitis. Pak J Surg 2014; 30(1): 36-39.

8. Aslam S, Ali M, Ahmed A, Asghar A, Manzar MA. Efficacy of functional endoscopic sinus surgery in recurrent nasal polyposis. Pak Armed Forces Med J 2014; 64(1); 66-70.

9. Sandhaus $H$, Chen PG. Intraoperative functional endoscopic sinus surgery training: Efficient teaching techniques- A new method. Clin Med Insights Ear Nose Throat 2018; 11(1): 3-4.

10. Fetta M, Tsilis NS, Segas JV, Nikolopoulos TP, Vlastarakos PV. Functional endoscopic sinus surgery improves the quality of life in children suffering from chronic rhinosinusitis with nasal polyp. Int J Pedia Otorhinolaryngol 2017; 100(3): 145-48.

11. Gohar MS, Niazi SA, Niazi SB. Functional endoscopic sinus surgery as a primary modality of treatment for primary and recurrent nasal polyposis. Pak J Med Sci 2017; 33(1): 380-82.

12. Nagalikar S, Rathod CV, Pillai RM, Manjunath S. A prospective study of role of FESS in management of recurrent nasal polyposis. Ind J Pub Health Res Dev 2013; 4(3): 257-61.

13. Chopra H, Khurana AS, Munjal M. Role of F.E.S.S. in chronic sinusitis. Ind J Otolaryngol Head Neck Surg 2006; 58(4): 137-40.

14. Razzak MA, Alam MK, Rahman MW, Islam SS, Hossain MR, Amin ZA. Functional endoscopic sinus surgery (FESS) for the Management of Chronic rhinosinusitis. Bang J Otorhiniolaryngol 2020; 23(2): 122-26. 
15. Siam S, Elawady M, Elemery O. Assessment of endoscopic sinus surgery in management of sinonasal diseases. Egypt J Hosp Med 2018; 73(10): 7794-05.

16. Qureshi N, Arif N. Functional endoscopic sinus surgery (FESS). J Rawal Med Coll 2017; 21(1): 78-81.
17. Raza M. Extended application of functional endoscopic sinus surgery in ophthalmology and neurosurgery. Pak Armed Forces Med J 2018; 68(4): 876-72.

18. Kumar S, Singh M, Singh B, Singh A. Role of FESS in nasal polyposis. J Evol Med Dent Sci 2018; 7(13): 1592-96. 